REVIEW AND SYNTHESIS PAPER

\title{
Marine Citizen Science: Recent Developments and Future Recommendations
}

\author{
Andrew Sandahl* and Anders P. Tøttrup ${ }^{\dagger}$
}

\begin{abstract}
Marine Citizen Science (MCS) is highly underrepresented in the citizen science literature, despite the instrumental (data-focused) and capacity-building (society-focused) benefits such projects offer for marine conservation. Nevertheless, the MCS literature has experienced continual growth since its first publications in the early 1990s. Few reviews have considered the developing history of MCS, and none have considered recent developments in the field. By reviewing 185 MCS papers published from 20142018, this study examines recent developments in MCS and offers informed recommendations for future MCS projects. Over the five surveyed years, there were significant increasing trends in both MCS publication quantity and diversity of affiliated research countries, although many tropical study regions with high observation potential remained underrepresented. Sixty-eight percent $(68 \%, N=126)$ of surveyed MCS studies focused on non-emblematic study subjects versus thirty-two percent (32\%, $N=59$ ) of studies that focused on emblematic subjects (e.g., coral reefs, megafauna, and endangered/critically endangered species found on the Red List of Threatened Species compiled by the International Union for Conservation of Nature [IUCN]), suggesting that the charismatic appeal of the scientific topic may not be a limiting factor to volunteer participation. Nearly $82 \%(N=151)$ of studies failed to describe explicit hypotheses, and many studies utilizing novel data neglected to include descriptions of data quality assurance measures $(25 \%, N=47)$ in their reports, potentially fueling the credibility challenge, which citizen science research faces as a whole. Finally, only a small portion of studies $(10 \%, N=19)$ involved participants beyond mere data collection, despite the unique and diverse perspectives volunteers may bring to scientific research. Collectively, these results aid in forming a set of recommendations for future MCS projects seeking to improve the quality of their credibility, study design, and volunteer contributions through explicitly stating hypotheses/quality-insurance methods, considering the potential of non-emblematic study species/ smartphone applications, and designing projects that allow for a spectrum of volunteer participation in high-observation potential areas.
\end{abstract}

Keywords: literature review; recommendations; collaborative projects; study species; volunteer participants

\section{Introduction and Objectives}

Since citizen science was first mentioned in 1989 (Haklay 2015), the field has experienced a steady increase in popularity, particularly in the field of ecology (Follett and Strezov 2015). This increase in popularity likely stems from a variety of factors, including a growing realization among scientists of the potential skills represented by the volunteer participants (Silvertown 2009). In addition to fulfilling these labor-focused, instrumental goals, citizen science also addresses socially focused, capacity-building goals by inspiring, educating, and engaging members of the public in scientific issues (Ceccaroni et al. 2017). These capacity-building goals may also serve to enhance social license, the unwritten consent from the public for govern-

\footnotetext{
* University of Amsterdam, NL

Natural History Museum of Denmark, University of Copenhagen, DK

Corresponding author: Andrew Sandahl (asandahl@ucla.edu)
}

ment or other institutions to manage natural resources, through building marine citizenship and ocean literacy among volunteers (Kelly et al. 2019). To accomplish these instrumental and capacity-building goals, citizen science projects involve volunteers in one or more steps in the scientific process (Shirk et al. 2012), although contributory projects, in which volunteers act primarily as data collectors, tend to be most common. Less common are collaborative projects (projects in which volunteers participate beyond data collection) and co-created projects (projects which are jointly developed and executed, and results are reported by scientists and members of the public) (Shirk et al. 2012).

Although citizen science projects occur in a wide range of environments, the marine environment seems particularly underrepresented in the citizen science literature. Despite making up $70 \%$ of the earth's surface, marine environments were studied in only $14 \%$ of citizen science projects globally surveyed in 2012 (Roy et al. 2012). This underrepresentation of marine citizen science is likely a 
result of the unique challenges that marine environments present. Still, marine citizen science (MCS), which can be defined as citizen science that studies at least some aspect of the marine environment, has been experiencing steady growth over recent decades (Thiel et al. 2014), as well as high levels of interest among marine users (Martin et al. 2015). MCS projects can occur in a wide variety of marine environments, including the coastal (Hidalgo-Ruz and Thiel 2013), intertidal (Delaney et al. 2008), neritic (Hesley et al. 2017), and oceanic zones (Horne 2013). Similar to its terrestrial counterparts, MCS projects also tend to focus primarily on biodiversity monitoring (Thiel et al. 2014; Hyder et al. 2015), although a variety of other phenomena have been studied as well, including the spread of invasive species (Delaney et al. 2008), pollution (Anderson and Alford 2014), and the categorization of whale calls (Shamir et al. 2014).

Despite their relative scarceness, marine-based projects may be especially suited for citizen science, particularly with respect to the importance of the instrumental and capacity-building benefits that citizen science can offer to the marine environment. For example, having a large number of volunteers increases the temporal and spatial surveying scale, which is particularly meaningful for projects occurring in the marine environment, as more than $80 \%$ of the oceans are estimated to be unmapped and unobserved (NOAA 2018). Furthermore, the capacitybuilding goals (i.e., education, engagement, and inspiration) accomplished through citizen science are especially pertinent to marine environments, as $37 \%$ of humans may depend on the marine resources provided by the coastal communities in which they live (United Nations 2017). Capacity-building benefits of MCS include producing a skilled task force and an ocean-literate community (Schläppy et al. 2015; Kelly et al. 2019), thereby creating a community better prepared to protect the resources on which they may depend. By increasing monitoring efforts and empowering members of the public to take political action to protect the oceans, MCS projects may help to address such critical problems as rising sea levels, overfishing, and ocean acidification.

In contrast to these benefits, the marine environment also presents many challenges to citizen science projects, chief of which is the inaccessibility of some parts of the study environment. As terrestrial beings, humans require either special skills or transportation to access most marine environments, which can be both prohibitive and costly (Cigliano et al. 2015). Additionally, MCS may be limited by the $40 \%$ of the population that does not live in coastal areas (Hyder et al. 2015) and therefore cannot easily travel to study areas, as well as by the cultural and individual differences in how people relate to the sea (Jefferson et al. 2015). A variety of subjectively uncharismatic marine study subjects (i.e., microfauna, pollution) (Jones et al. 2018) and the underutilization of volunteers' potentially unique, out-of-the-box perspectives (Lukyanenko et al. 2016) may also present room for improvement in volunteers' contributions. For example, volunteers may have valuable insights into project design or data analysis, which go unnoticed when volunteers are viewed solely as data collectors (Lukyanenko et al. 2016).
Furthermore, MCS suffers from challenges related to citizen science generally, such as the credibility challenge, which can make convincing the scientific community of the trustworthiness of volunteer-collected data particularly difficult (Freitag et al. 2016). Addressing these issues will be critical to designing successful MCS projects in years to come.

Amidst the benefits and challenges of MCS, there surely lie opportunities to improve the design and implementation of future projects. Many studies have previously attempted to offer recommendations for citizen science projects. These recommendations can be highly specific to a single aspect, such as properly understanding volunteer motivation (Hermoso et al. 2019; Martin et al. 2015; West and Pateman 2016); incredibly broad, such as offering overarching principles for citizen science project design (Silvertown 2009); or they can be presented in the form of tool kits designed to tailor guidelines to the ultimate goal of the project (Cigliano et al. 2015). While such recommendations are useful, they rarely consider large samples of previously published projects, and often are not specific to marine-based projects (but see Thiel et al. 2014).

Although underrepresented, marine citizen science stands as a rapidly growing field (Thiel et al. 2014). Therefore, our study seeks to offer an updated look at the state of MCS through a broad survey of recently published literature. Specifically, our study examines four different research areas, including (1) trends in quantity and research/researcher locations of published MCS studies, (2) differences in the representation of emblematic and non-emblematic study subjects, (3) differences in the representation of descriptive and hypothesis-based studies, and (4) differences in the representation of contributory and collaborative participation models in recent MCS literature. By analyzing MCS literature published within the past five years (2014-2018), this study will present a broad look at the current state of MCS, as well as offer informed recommendations for future projects.

\section{Methodology}

A literature review was conducted of MCS studies published within the last five years to elucidate current research trends, geographic tendencies, and opportunities for growth. Given that Thiel et al. (2014) already performed a comprehensive MCS review up to 2014, this review focused solely on studies published from 2014-2018. Searches were conducted in Web of Science, Scopus, and Google Scholar databases between January and February 2019, using the topical search terms "marine citizen science," "ocean citizen science," "coastal citizen science," and "marine volunteer" individually. All literature encountered in Web of Science and Scopus databases, as well as the first fifty studies encountered in Google Scholar, was examined, and only papers meeting at least one of the following two criteria were retained: (1) studies or reviews that clearly involved members of the public in marine research, (2) studies or reviews that used previously collected, marine-based data, which were clearly gathered by members of the public. For this review, members of the public were defined to be anyone except professional marine scientists or marine science students. Literature 
that (1) gave a synopsis of multiple case studies within a single paper, (2) included biology students as members of the public, or (3) involved the public merely for an attitude/perspective survey were not included.

Once all literature had been collected, each study or review was further examined to elucidate trends in recent MCS literature. Variables included year published, study subject, study species, researcher country, research country, study area, study habitat, public participation model, marine skills used, study type, study objective, data origin, data quality measures, and use of smartphone application.

The variable "study subject" was further sorted by emblematic and non-emblematic study subjects. Emblematic study subjects were defined by the authors as marine megafauna, endangered/critically endangered species (as identified by the IUCN), and coral reefs. Nonemblematic study subjects comprised all other study subjects, and included microfauna, invasive species, and marine pollution.

The variable "researcher country" was based on the country affiliations of the majority of each study's authors, and in the case of multiple, equally represented affiliations, both countries were recorded. This was done to examine which countries were initiating recent MCS research. In contrast, the "research country" variable was based on the country in which the study actually took place. This was done to examine the location of the actual citizen volunteers involved in these studies. Studies that took place across entire oceans or seas were categorized as global.

Furthermore, each research country was categorized as being either tropical (0-23.5 latitude), subtropical (23.5$35^{\circ}$ latitude), or temperate/polar (greater than $35^{\circ}$ latitude). Only three studies found were performed in polar environments (Bergmann et al. 2017; Enoksen and Reiss 2018; Storrie et al. 2018), and thus this category was combined with the temperate studies category. The effects of seas on climate were also taken into account when classifying research countries; for example, the entire Caribbean Sea was classified as tropical (despite extending beyond $23.5^{\circ} \mathrm{N}$ ), while the entire Mediterranean Sea was classified as subtropical (despite extending beyond $35^{\circ} \mathrm{N}$ ). Any extraordinary aspects of the studies (such as citizens initiating projects or performing laboratory work) were also noted as the literature was examined.

The variable "study type" was categorized to include species-based studies, pollution-based studies, and environment-based studies. Species-based studies were defined as studies that focused exclusively on one or more biological species. Pollution-based studies were defined as studies that focused on some aspect of marine pollution, such as beach litter. Environment-based studies were defined as studies that focused on all other aspects of the marine environment, such as water quality, ecosystem health, or ecosystem restoration.

The variable "study objective" was categorized into five different types- population monitoring (studies that collected biological data of a single species), survey (studies that collected biological data of multiple species), conservation (studies that focused on pollution or invasive species eradication), environmental monitoring (studies that collected data on abiotic variables, such as water quality), and discovery (studies that used volunteer data to document a new species or new species range).

The variable "public participation model" was categorized on the basis of the typology set forth by Ceccaroni et al. (2017), with contributory projects defined as projects in which volunteers merely contributed data, and collaborative projects as studies in which volunteers participated in the scientific process beyond mere data collection. Discoverybased projects, in which citizen volunteers were responsible for the discovery of a previously unknown species or species range, were also classified as collaborative projects.

All data were analyzed using $\mathrm{R}$ Studio (R Core Team 2017), and world maps were produced using the ggplot $2 \mathrm{R}$ package (Wickham 2016). Research areas 2-4 (differences in the representation of emblematic and non-emblematic study subjects, differences in the representation of descriptive and hypothesis-based studies, and differences in the representation of contributory and collaborative participation models in recent MCS literature) were examined using annual counts of the specified variable, and non-parametric tests were used to account for the small sample size. A complete list of surveyed literature is recorded in Supplemental File 1: Appendix.

\section{Results}

Many of our results echoed the findings of Thiel et al. (2014), and novel findings were also elucidated. In this section, we describe results focused on location, study subject, study type, and the participatory model used.

\section{Trends in quantity and researcher/research locations} of published marine citizen science (MCS) studies

A total of 185 studies were retained in our literature survey of MCS studies published from 2014 to 2018. We found a significant increasing trend in the number of published studies $\left(p=0.003, R^{2}=0.931\right.$, linear regression analysis) from 2014, when 17 studies were published, to 2018, when 59 studies were published (see Figure 1).

A significantly increasing trend in richness of researcher countries contributed to these studies $\left(p=0.02, R^{2}=0.873\right.$, linear regression analysis), covering every continent with the exception of Antarctica. However, the majority of these publications were developed by researchers from just three countries, including the United States $(\mathrm{N}=42)$, Australia $(\mathrm{N}=41)$, and the United Kingdom $(\mathrm{N}=16)$. Indeed, the top five countries initiating MCS research (researcher countries) made up nearly $66 \%$ of the MCS literature published from 2014 to 2018, despite decreased contributions by many of these top-contributing countries in 2017 and/or 2018 (see Figure 2).

Occasional decreases in literature contributions from top-contributing countries were balanced by an increasing richness of countries initiating MCS research from 2014 to 2018. Indeed, the richness of researcher countries contributing to MCS literature nearly tripled over the five years, from just 9 contributing countries in 2014, to 24 contributing countries in 2018. Furthermore, the top contributing researcher country for each year made up a decreasing proportion of the total literature published that year, falling from 35\% of all papers published in 2014 to only $16 \%$ in 2018. 


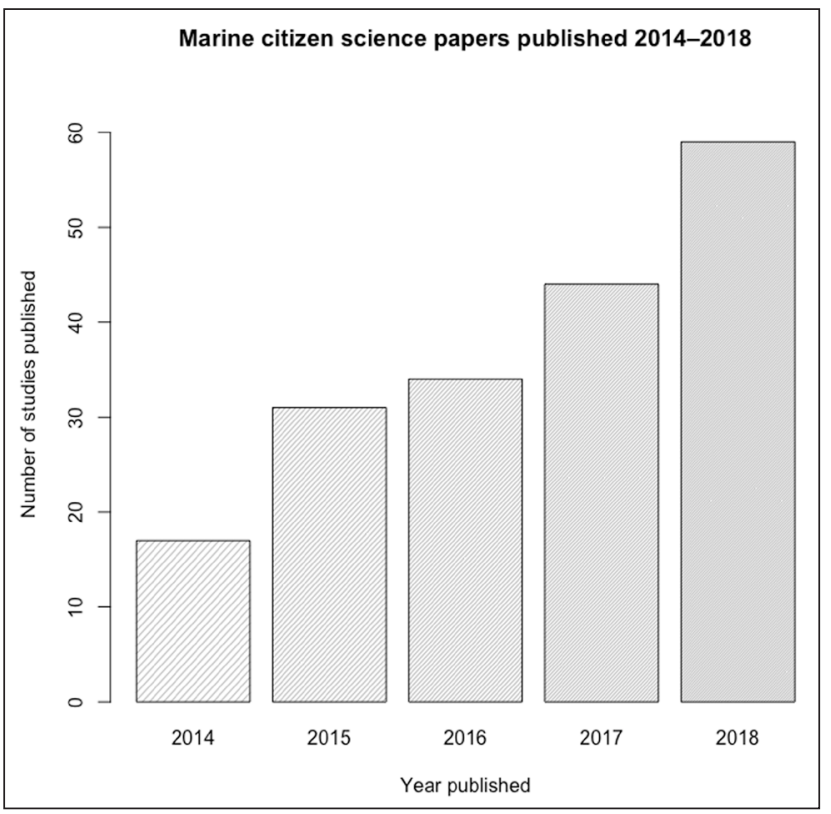

Figure 1: Total marine citizen science (MCS) literature encountered from 2014 to 2018. MCS literature has been experiencing a steady growth in publication since its beginnings in the early 1990s, which is a trend that continues today (9.7 new papers per year, based on a linear model).

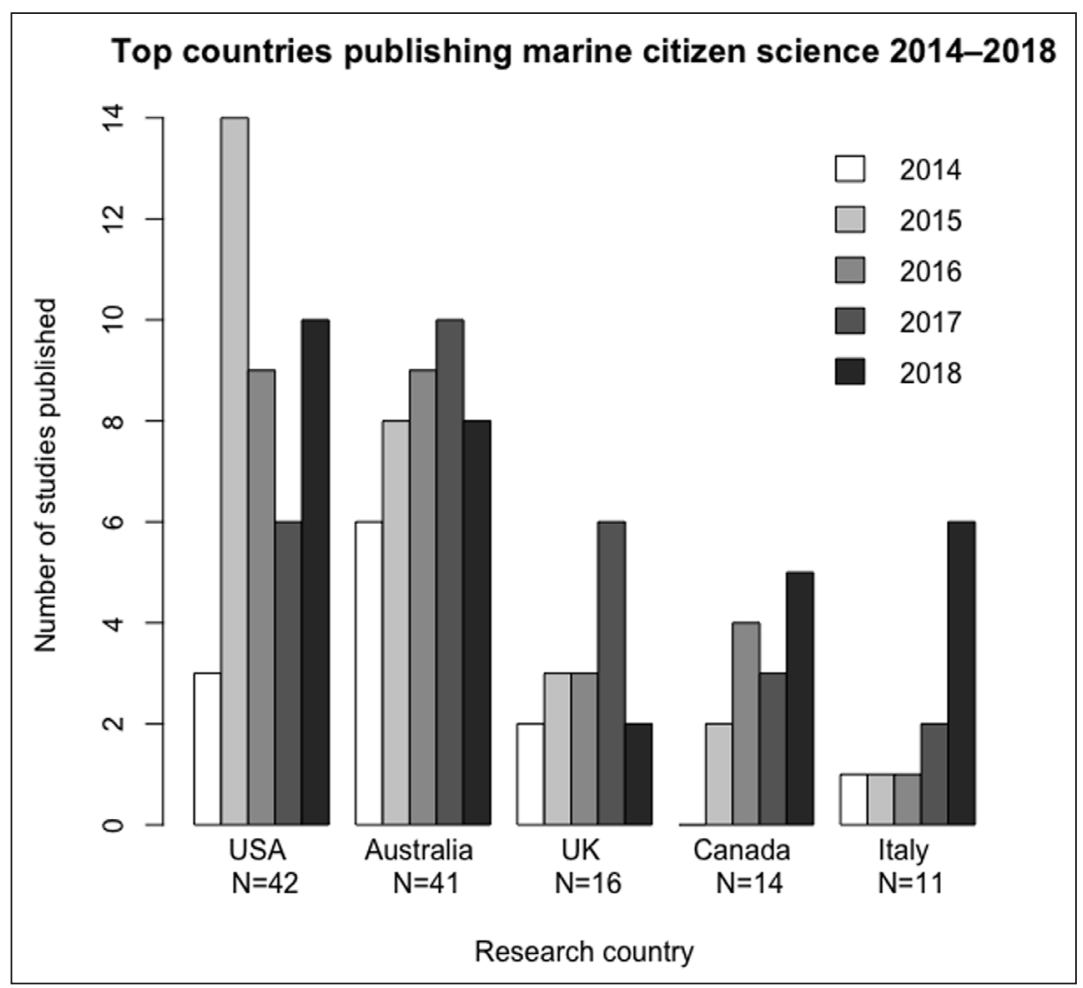

Figure 2: Bar plot showing marine citizen science (MCS) literature contributions for the top five contributing researcher countries, ordered from 2014 to 2018. Despite occasional decreases in contributions from major countries, MCS continued to grow through 2018 as a result of the increased diversity of contributing researcher countries.

Although it is possible that researchers perform their research abroad, nearly $81 \%$ of MCS studies surveyed were performed in countries matching the authors' main affiliation(s) $(\mathrm{N}=149)$. Of the remaining 36 studies, 20 were classified as having been performed globally (across an entire ocean or sea), and the other 16 studies as having been performed in countries differing from the authors' affiliations. Figure $\mathbf{3}$ shows the research locations of the 165 MCS studies surveyed (20 global studies excluded), highlighting that even when looking at research location, the USA $(\mathrm{N}=38)$, Australia $(\mathrm{N}=36)$, and the UK $(\mathrm{N}=12)$ remain top contributors.

It might be thought that MCS takes place primarily in tropical regions where the conditions for field work are more favorable. However, our study found that tropical studies (defined as studies taking place in locations between 0 and $23.5^{\circ}$ latitude) made up decreasing quantities of MCS studies published from 2014 to 2018, while 
subtropical and temperate/polar studies (taking place in locations at latitudes greater than $23.5^{\circ}$ ) made up increasingly more of MCS studies (see Figure 4). In fact, by 2018 , temperate/polar MCS studies (taking place in locations greater than $35^{\circ}$ latitude) made up the majority $(38 \%)$ of studies, while tropical and subtropical studies each contributed to $31 \%$ of MCS studies published that year.

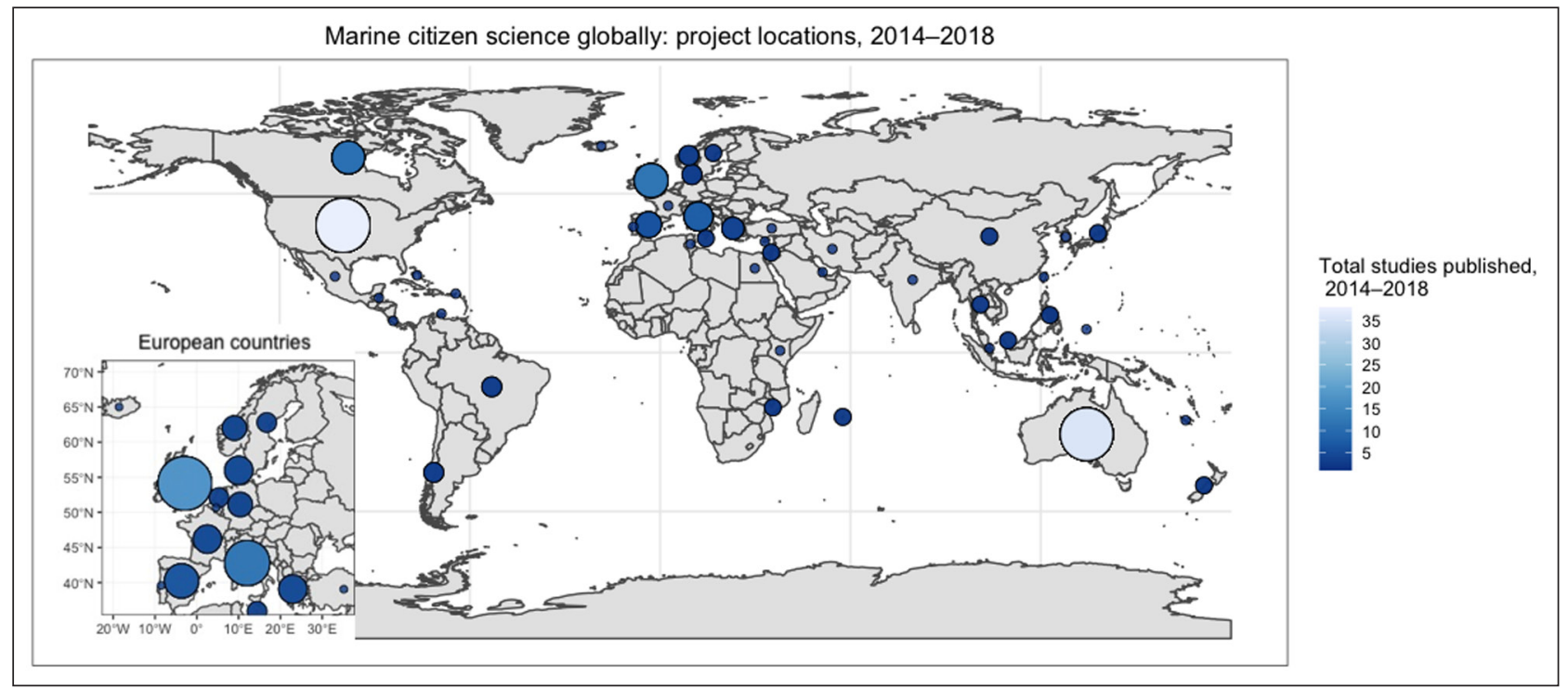

Figure 3: World map displaying country locations of marine citizen science research published from 2014 to 2018 , with European inset. Data points are scaled and colored to indicate total contributions from each country for these years. Although a total of 44 locations are represented, the majority of publications come from only three countriesAustralia, the United Sates, and the United Kingdom.

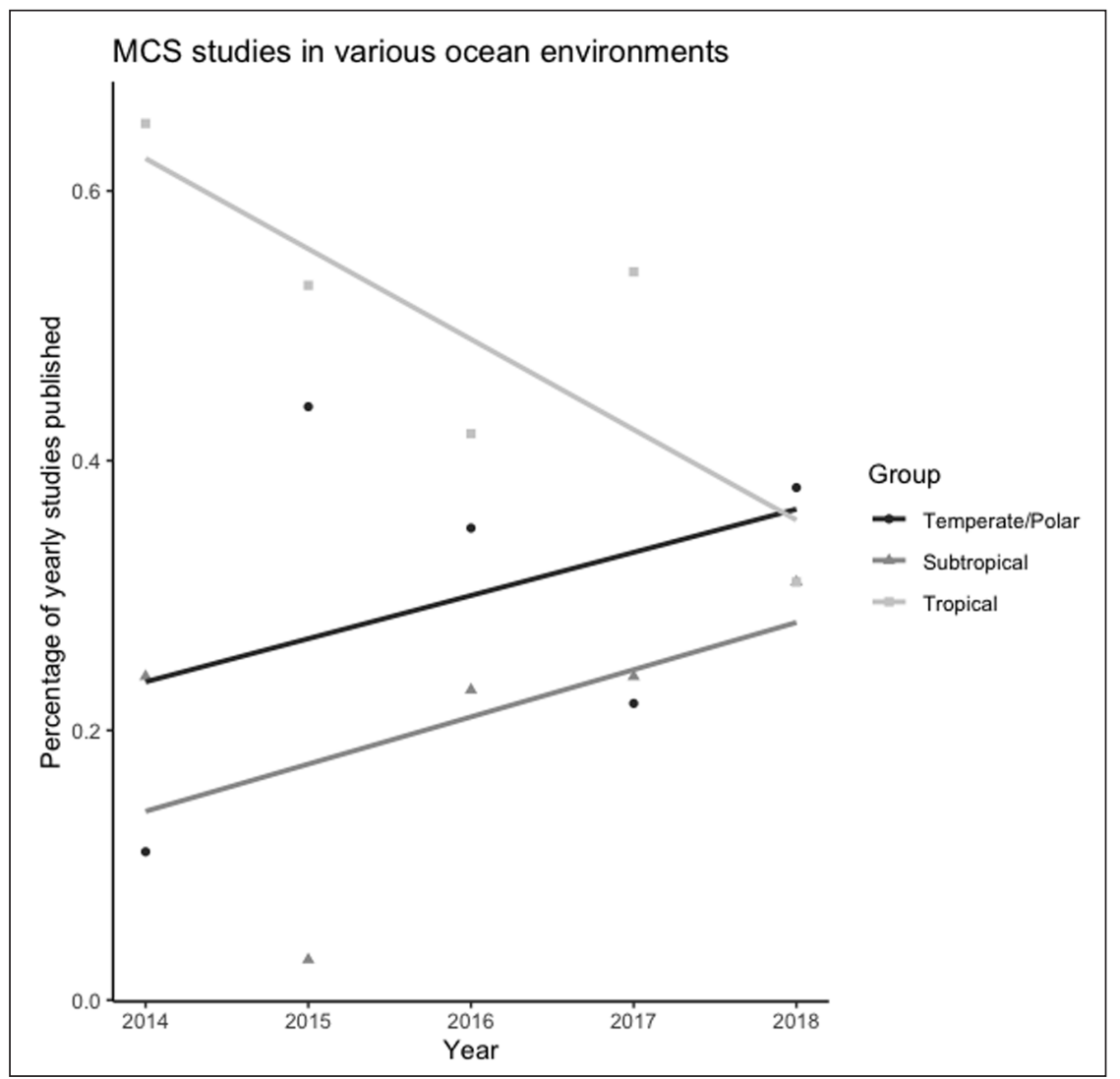

Figure 4: Scatter plot showing the percentage of published marine citizen science (MCS) studies undertaken in temperate/polar, subtropical, and tropical environments respectively. Contrary to common belief, from 2014 to 2018 there has been an overall decreasing trend in tropical MCS studies and increasing trends in subtropical and temperate/polar studies. The decreasing trend in tropical studies from 2014 to 2018 is not significant $\left(p=0.09, R^{\wedge} 2=0.67\right)$ unless the outlier point from 2017 is removed $\left(p=0.02, R^{\wedge} 2=0.96\right)$. 


\section{Emblematic and non-emblematic study subjects}

A high diversity of study subjects was found among the 185 studies examined. Most studies $(\mathrm{N}=129)$ focused on faunal or floral species, 35 studies focused on some aspect of marine pollution, and 21 studies focused on other environmental aspects, such as restoration or ecosystem health. In total, $32 \%$ of the studies $(\mathrm{N}=59)$ focused on emblematic subjects (defined as coral reefs, marine megafauna, or endangered species). Annual means of studies focusing on emblematic or non-emblematic species were not significantly different from one another (Wilcoxon signed rank test, $p=0.056$ ). Additionally, of the 129 species-based studies (defined as studies that focused exclusively on one or more biological species), nearly $86 \%$ focused on particular faunal species, with species of saltwater fish $(\mathrm{N}=50)$, marine mammals $(\mathrm{N}=17)$, and mollusks ( $\mathrm{N}=12$ ) being most popular (see Table 1). Overall, population monitoring of a single faunal species in coastal waters was the most common study design (see Figure 5).

\section{Descriptive and hypothesis-based studies}

The vast majority of studies published each year were descriptive in nature, while significantly fewer studies mentioned explicit hypotheses in their introduction/ methods section (18\% overall, Wilcoxon signed rank test, $p=0.012)$. Additionally, $9 \%$ of all studies $(\mathrm{N}=17)$ incorporated a smartphone application in their study design. SCUBA and/or snorkeling experience was required for $32 \%$ of the surveyed studies $(\mathrm{N}=60)$. In terms of data origin, $63 \%$ of all studies $(\mathrm{N}=117)$ produced novel data whereas the rest incorporated, to at least some extent, previously collected citizen science data. Finally, 40\% of the studies that produced novel data $(\mathrm{N}=47)$ had no mention of any measures taken, such as volunteer training or data verification, to assure the quality of citizencollected data.

\section{Contributory and collaborative participation models}

Significantly fewer studies worked with their citizen volunteers in a collaborative rather than contributory participation model (Wilcoxon signed rank test, $p=0.012$ ). The approximately $10 \%$ of studies that collaborated with volunteers throughout the research process include examples of citizen volunteers cultivating and transplanting species of coral (Horoszowski-Fridman et al. 2015; Toh et al. 2017), developing and implementing genetic laboratory techniques (Borg et al., 2016), and contacting researchers to propose data collection during recreational expeditions (Gewert et al. 2017). However, there was no significant trend in collaborative projects over the past five years.

Table 1: Table showing marine citizen science study subjects encountered in published literature from 2014 to 2018. The large quantity of un-emblematic subjects may indicate that the charismatic appeal of study subjects is not as critical as previously thought in recruiting volunteers for marine projects.

\begin{tabular}{|c|c|c|c|}
\hline Study subject & \# of studies & Study subject & \# of studies \\
\hline Fauna: & 113 & Flora: & 2 \\
\hline Marine mammals & 17 & Mangroves & 1 \\
\hline Cetacea & 16 & Seaweed & 1 \\
\hline Sirenia & 1 & & \\
\hline Saltwater fish & 50 & Other: & 70 \\
\hline Elasmobranchii & 12 & General faunal species & 11 \\
\hline Osteicthyes & 38 & General faunal and floral species & 2 \\
\hline Marine reptiles & 7 & Plankton & 3 \\
\hline Chelonioidea & 6 & Reef ecosystem & 1 \\
\hline Elapinae & 1 & Debris & 31 \\
\hline Sea birds & 10 & Oil & 1 \\
\hline Crustaceans & 6 & Environment & 21 \\
\hline Mollusks & 12 & & \\
\hline Bivalvia & 8 & Emblematic species? & \\
\hline Cephalopoda & 2 & Yes & 59 \\
\hline Gastropoda & 2 & No & 126 \\
\hline Cnidarians & 9 & & \\
\hline Anthozoa & 5 & & \\
\hline Scyphozoa & 4 & & \\
\hline Echinoderms & 2 & & \\
\hline
\end{tabular}




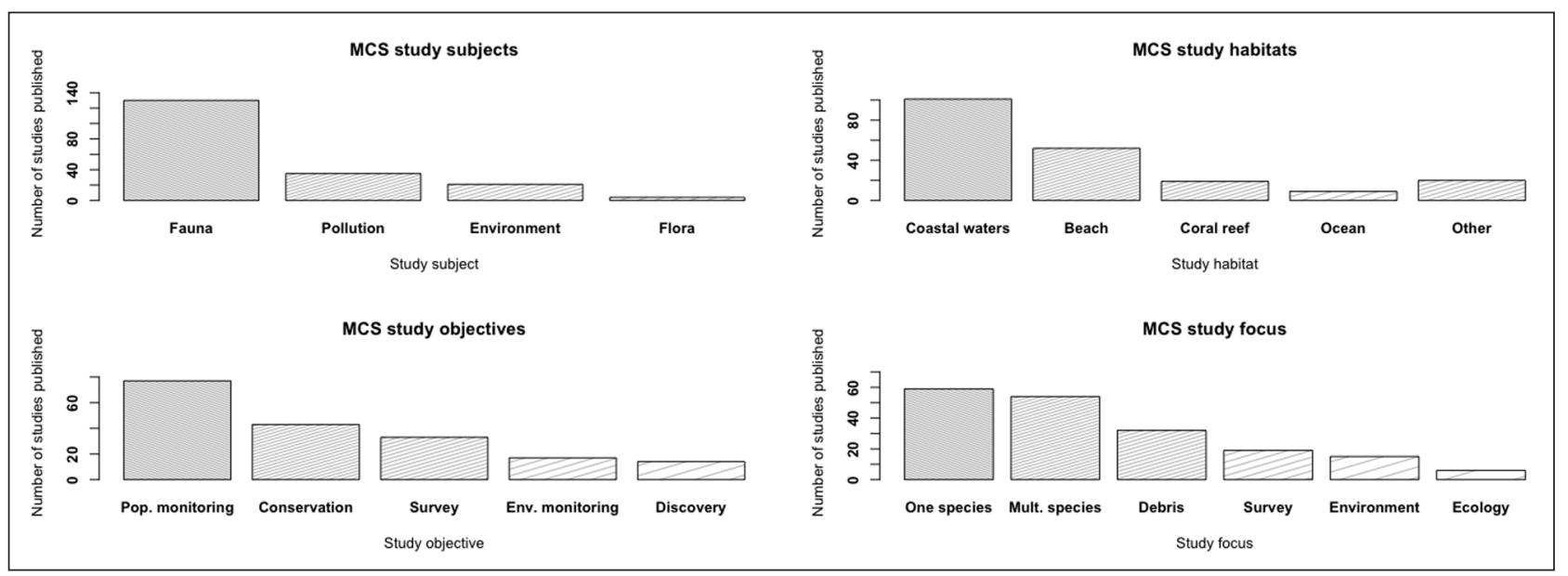

Figure 5: Bar plots showing various aspects of marine citizen science (MCS) studies surveyed from 2014 to 2018 . Studies that focused on single or multiple faunal species, on coastal water habitats, or on population monitoring were most common. The "other" category listed in study habitats consists of a variety of less-represented categories, including wetlands, estuaries, rocky reefs, and intertidal regions.

\section{Discussion}

The results of this literature survey show that MCS continues to experience growth, as predicted by Thiel et al. (2014). Perhaps more surprising is that this growth comes in part as the result of an increased diversity of contributing researcher countries, indicating that MCS appears to be gaining global popularity. Overall, the majority of studies were researched in the same countries as the authors' affiliation, highlighting that MCS volunteers are generally drawn from the authors' home country.

As similarly reported in Thiel et al. (2014), the MCS studies examined in this survey tended to be both initiated and carried out in more economically developed countries with relatively long coastlines such as the United States, Australia, and the United Kingdom. Still, this review shows examples of less developed countries participating in MCS research, including many countries in Southeast Asia and a few in Central/South America and Africa (see Figure 2). However, these few examples are hardly commensurate with the vast observation potential (high biodiversity and high human populations) that lies within many tropical countries (Pocock et al. 2018), indicating that these tropical regions remain a largely underutilized MCS resource.

A variety of study subjects were also used in the 185 papers surveyed in this literature review, consisting of floral and faunal species, pollution, and other aspects of the marine environment. The proportional abundances of these categories in the published literature is similar to those described by Thiel et al. (2014), with floral and faunal species making up the vast majority of study subjects, followed by pollution/contamination. Although some study subjects can be researched quite easily from shore or with minimal volunteer training, other subjects can be more difficult. For example, identifying marine species often requires specialized training or the ability of volunteers to either SCUBA dive or snorkel, which for some researchers can present a challenge. These challenges can be overcome, however, by focusing on mammalian, avian, or intertidal species, which can be identified above water; by working with anglers who are able to identify and tag individuals at the surface; or by utilizing data previously collected by dive clubs. Indeed, many of the surveyed studies adopted well-established methods, as evidenced by the $37 \%$ of total studies that incorporated previously collected data. Also, many (31\%) of the faunal studies focused exclusively on marine mammals, seabirds, or intertidal bivalves, which are well known by hobby naturalists. Implementing methods such as these in citizen science projects aided in producing the $68 \%$ of surveyed studies that required no SCUBA or snorkeling experience from volunteers.

More than two thirds of studies surveyed did not focus on emblematic features (defined by the authors as marine megafauna, coral reefs, or endangered species). This suggests that the attractiveness (i.e., the emblematic appeal) of the study subject may not play a critical role in the recruitment and engagement of marine volunteers. Indeed, the attractiveness, or appeal, of the marine environment (even in colder, temperate regions) may be motivation enough for many volunteers to participate in scientific studies. Perhaps researchers need not focus their citizen science projects primarily around emblematic study subjects. Instead, researchers might strive to demonstrate to volunteers the impact of certain study subjects on the marine environment, as this could serve as an alternative motivator to members of the public. This is exemplified by the $17 \%$ of surveyed projects that studied the unglamorous subject of marine pollution, but also less obviously by the $33 \%$ of surveyed faunal studies that focused on (mostly) non-emblematic bony fish species, many of which were invasive (as indicated by the studies) (i.e., the lionfish derbies in Malpica-Cruz et al. 2016). Indeed, the motivations of MCS volunteers may be focused less on study subjects and more on other aspects, such as the ability to contribute to scientific knowledge (Martin et al. 2016b).

As is common in citizen science studies, the vast majority of surveyed projects (82\%) were descriptive in nature, lacking any explicitly defined hypotheses. This inductive approach to science, while thoroughly important to scientific advancement, may influence the view that citizen 
science serves only to complement alternative, hypothesis-driven research (Dickinson et al. 2010). However, the successful publication of so many descriptive MCS studies may also indicate the scientific community's growing acceptance of such descriptive studies. Still, to counter the perception of citizen science as merely complementary science within the scientific community, researchers may strive to incorporate hypothesis testing into their study designs whenever possible.

There has also been an increase in the use of smartphone applications in MCS studies over the past years. Although smartphone applications have been used in projects from 2015 to $2018,75 \%$ of the projects (12 of 16 total studies) utilizing smartphone applications in their study design were published in just the last two years (2017-2018). This increase in smartphone application usage underscores the prevalence of such devices globally, and researchers seeking to streamline data collection might consider the use of smartphone applications to achieve this (Compas and Wade 2018; Martin et al. 2015). Electronic databases such as Redmap (Range Extension Database and Mapping Project) have already shown the power of technology to overcome many of the classic MCS data organization challenges (Nursey-Bray et al. 2018). Indeed, MCS volunteers may actually prefer the use of such technological interfaces to assist in data collection, and might be less likely to participate in projects without them (Martin et al. 2016a).

An incredibly important aspect of citizen science has always been the assurance of high-quality, trustworthy data. Adequately describing measures taken to assure quality, such as thorough data verification or volunteer training, is therefore critical for addressing the credibility challenge (Freitag et al. 2016) that citizen science studies face. However, of the papers producing novel data from 2014 to 2018, 40\% included no mention of any such measures being implemented. When contrasted with the $45 \%$ of studies that included no quality control measures reported in Thiel et al. (2014), it becomes evident that recent MCS research has seen a slight increase in the utilization of quality control methods. Still, neglecting to use quality control methods in $40 \%$ of MCS studies is substantial. It is unlikely that so many studies offered absolutely no training or data verification opportunities to their volunteers, and thus it may be that many studies have simply missed the opportunity to describe such details in their methods. To prevent such omissions from affecting the perceived reliability of a project's results, studies should not only implement data quality assurance measures (Schläppy et al. 2017), but also explicitly note such measures in their methods. In addition to volunteer training and data verification by an expert, iterative project development, replication across volunteers, and statistical modeling of systematic error may aid in assuring high-quality, trustworthy data (Kosmala et al. 2016).

Finally, it is important to discuss the participation models used throughout the 185 surveyed studies. Of these studies, 90\% employed a contributory participation model (see Ceccaroni et al. 2017). Clearly, the contributory model of participation is highly utilized in the field of citizen science. This may be to the benefit of volunteers, as studies have shown some MCS participants are primarily interested in data collection opportunities and prefer simple sampling protocols (Hermoso et al. 2019; Martin et al. 2016c). Still, non-scientist volunteers harbor a variety of unique perspectives that can provide "fertile ground for discoveries" (Lukyanenko et al. 2016, p. 447) beyond data collection, as evidenced by the 14 discovery-based studies surveyed. The 4 non-discovery-based collaborative projects identified herein (e.g., Ceccaroni et al. 2017) provide further evidence of the benefits conferred from volunteers' unique perspectives. For example, the adventurous spirit seen in two data-collecting paddle boarders who initiated a project that pulled lightweight trawls across the Baltic Sea (Gewert et al. 2017) and the curiosity of volunteers who helped define and design a genetic study on bacterioplankton (Borg et al. 2016) offer opportunities for MCS. Indeed, examples such as these serve to emphasize the claim made by Lukyanenko et al. (2016) that "data quality in citizen science is much more than data accuracy" (p. 447). By designing research projects that allow for a spectrum of volunteer participation, researchers might take full advantage of the unique perspectives non-professional participants bring to science, while still respecting the majority of participants' desire to focus solely on data collection.

\section{Conclusion and Recommendations}

MCS, although underrepresented in the citizen science literature (Roy et al. 2012), is a rapidly growing field of great importance to scientists and the public alike. The increased spatial and temporal sampling scales afforded by citizen science have allowed for increased monitoring in the highly unexplored marine environment, and the increased social engagement that citizen science strives for has fostered increased public support for marine conservation (Dean et al. 2018; Thiel et al. 2014). Still, many challenges and opportunities exist for this field, which future MCS projects may find fruitful to consider.

To begin, future projects might better address the credibility challenge by including both explicit hypotheses and measures taken to assure data quality in their reports. This is not to say that descriptive research is not valuable, as it undoubtably is. However, despite attempting to meet the same standards of credibility as traditional science, citizen science operates within a different context, which can make establishing credibility especially difficult (Freitag et al. 2016). Indeed, many scientists are doubtful of the public's ability to contribute to science (Golumbic et al. 2017), considering citizen science as a mere complement to hypothesis-driven research (Dickinson et al. 2010). Explicitly stating hypotheses and data quality-assurance measures could help to increase the academic credibility of such studies and the field of citizen science generally.

Future projects may also wish to consider the role of non-emblematic species and smartphone applications when designing their studies. Researchers need not be overly concerned with the charismatic appeal of their study subject when designing MCS projects, as over two thirds of studies surveyed focused on non-emblematic subjects, many of which were in cold, temperate waters. 
Instead, researchers might strive to demonstrate the general importance of the study topic, because the allure of the marine environment as a whole might be sufficient motivation to attract volunteers. The greatly increased use of smartphone applications in MCS projects in the past two years underscores the ubiquity of such devices for citizen science projects, and thus such technology should be at least considered when designing MCS projects.

Finally, future projects should consider taking measures to maximize the benefits that their volunteers are able to confer upon projects. Performing research in areas of high observation potential is especially important for citizen science projects, and many such areas of high biodiversity and high human populations are found in the tropics. Additionally, designing research projects that allow for a spectrum of volunteer participation, from contributory to collaborative, may allow for researchers to take full advantage of volunteers' unique perspectives, all while respecting their various motivations.

Marine citizen science shows no sign of slowing its growth in the coming years. As such, it is critical that future projects learn what they can from the short history of this emerging field, improving their own projects' success while laying an ever-stronger foundation upon which MCS may continue to build.

\section{Supplementary File}

The Supplementary file for this article can be found as follows:

- Supplemental File 1. Appendix: Complete list of MCS literature surveyed. DOI: https://doi.org/10.5334/ cstp. 270.s 1

\section{Competing Interests}

The authors have no competing interests to declare.

\section{Author Contributions}

Andrew Sandahl designed the study, performed the literature review, analyzed the data, interpreted the results and wrote the paper. Anders P. Tøttrup assisted in designing the study, interpreting the results, and revising the final paper.

\section{References}

Anderson, JA and Alford, AB. 2014. Ghost fishing activity in derelict blue crab traps in Louisiana. Marine Pollution Bulletin, 79(1-2): 261-267. DOI: https://doi. org/10.1016/j.marpolbul.2013.12.002

Borg, Y, Grigonyte, AM, Boeing, P, Wolfenden, B, Smith, P, Beaufoy, W, Rose, S, Ratisai, T, Zaikin, A and Nesbeth, DN. 2016. Open source approaches to establishing Roseobacter clade bacteria as synthetic biology chassis for biogeoengineering. PeerJ, 4: e2031. DOI: https://doi.org/10.7717/peerj.2031

Ceccaroni, L, Bowser, A and Brenton, P. 2017. Civic education and citizen science: Definitions, categories, knowledge representation. In: Ceccaroni, L and Piera, $\mathrm{J}$ (eds.), Analyzing the Role of Citizen Science in Modern Research. IGI Global. pp. 1-23. DOI: https://doi. org/10.4018/978-1-5225-0962-2.ch001
Cigliano, JA, Meyer, R, Ballard, HL, Freitag, A, Phillips, TB and Wasser, A. 2015. Making marine and coastal citizen science matter. Ocean \& Coastal Management, 115: 77-87. DOI: https://doi.org/10.1016/j.ocecoaman.2015.06.012

Compas, ED and Wade, S. 2018. Testing the waters: a demonstration of a novel water quality mapping system for citizen science groups. Citizen Science: Theory and Practice, 3(2): 1-11. DOI: https://doi. org/10.5334/cstp.124

Dean, AJ, Church, EK, Loder, J, Fielding, KS and Wilson, KA. 2018. How do marine and coastal citizen science experiences foster environmental engagement? Journal of environmental management, 213: 409-416. DOI: https://doi.org/10.1016/j.jenvman.2018.02.080

Delaney, DG, Sperling, CD, Adams, CS and Leung, B. 2008. Marine invasive species: validation of citizen science and implications for national monitoring networks. Biological Invasions, 10(1): 117-128. DOI: https://doi.org/10.1007/s10530-007-9114-0

Dickinson, JL, Zuckerberg, B and Bonter, DN. 2010. Citizen science as an ecological research tool: challenges and benefits. Annual review of ecology, evolution, and systematics, 41: 149-172. DOI: https://doi. org/10.1146/annurev-ecolsys-102209-144636

Follett, R and Strezov, V. 2015. An analysis of citizen science based research: Usage and publication patterns. PloS ONE, 10(11): 1-14. DOI: https://doi.org/10.1371/ journal.pone.0143687

Freitag, A, Meyer, R and Whiteman, L. 2016. Strategies employed by citizen science programs to increase the credibility of their data. Citizen Science: Theory and Practice, 1(1): 2. DOI: https://doi.org/10.5334/ cstp.6

Gewert, B, Ogonowski, M, Barth, A and MacLeod, M. 2017. Abundance and composition of near surface microplastics and plastic debris in the Stockholm Archipelago, Baltic Sea. Marine pollution bulletin, 120(1-2): 292-302. DOI: https://doi.org/10.1016/j. marpolbul.2017.04.062

Golumbic, YN, Orr, D, Baram-Tsabari, A and Fishbain, B. 2017. Between vision and reality: A study of scientists' views on citizen science. Citizen Science: Theory and Practice, 2(1): 6. DOI: https://doi.org/10.5334/ cstp.53

Haklay, M. 2015. Citizen science and policy: a European perspective. Washington, DC: Woodrow Wilson International Center for Scholars, 2015.

Hermoso, MI, Martin, V, Stotz, W, Gelcich, S and Thiel, M. 2019. How does the diversity of divers affect the design of citizen science projects? Frontiers in Marine Science, 6: 239. DOI: https://doi.org/10.3389/ fmars.2019.00239

Hesley, D, Burdeno, D, Drury, C, Schopmeyer, S and Lirman, D. 2017. Citizen science benefits coral reef restoration activities. Journal for Nature Conservation, 40: 94-99. DOI: https://doi.org/10.1016/j. jnc.2017.09.001

Hidalgo-Ruz, V and Thiel, M. 2013. Distribution and abundance of small plastic debris on beaches in 
the SE Pacific (Chile): a study supported by a citizen science project. Marine environmental research, 87: 12-18. DOI: https://doi.org/10.1016/j.marenvres.2013.02.015

Horne, R. 2013. Seeking sailors to help measure phytoplankton populations. Proceedings of the National Academy of Sciences, 110(18): 7107-7107. DOI: https://doi.org/10.1073/pnas.1306732110

Horoszowski-Fridman, YB, Brêthes, JC, Rahmani, N and Rinkevich, B. 2015. Marine silviculture: Incorporating ecosystem engineering properties into reef restoration acts. Ecological Engineering, 82: 201-213. DOI: https://doi.org/10.1016/j.ecoleng.2015.04.104

Hyder, K, Townhill, B, Anderson, LG, Delany, J and Pinnegar, JK. 2015. Can citizen science contribute to the evidence-base that underpins marine policy? Marine policy, 59: 112-120. DOI: https://doi.org/10.1016/j. marpol.2015.04.022

Jefferson, R, McKinley, E, Capstick, S, Fletcher, S, Griffin, $\mathbf{H}$ and Milanese, M. 2015. Understanding audiences: making public perceptions research matter to marine conservation. Ocean \& Coastal Management, 115: 61-70. DOI: https://doi.org/10.1016/j.ocecoaman.2015.06.014

Jones, BL, Unsworth, RK, McKenzie, LJ, Yoshida, RL and Cullen-Unsworth, LC. 2018. Crowdsourcing conservation: The role of citizen science in securing a future for seagrass. Marine pollution bulletin, 134: 210-215. DOI: https://doi.org/10.1016/j.marpolbul.2017.11.005

Kelly, R, Fleming, A, Pecl, GT, Richter, A and Bonn, A. 2019. Social License through Citizen Science: A Tool for Marine Conservation. Ecology and Society, 24(1). DOI: https://doi.org/10.5751/ES-10704-240116

Kosmala, M, Wiggins, A, Swanson, A and Simmons, B. 2016. Assessing data quality in citizen science. Frontiers in Ecology and the Environment, 14(10): 551-560. DOI: https://doi.org/10.1002/fee.1436

Lukyanenko, R, Parsons, J and Wiersma, YF. 2016. Emerging problems of data quality in citizen science. Conservation Biology, 30(3): 447-449. DOI: https://doi.org/10.1111/cobi.12706

Malpica-Cruz, L, Chaves, LC and Côté, IM. 2016. Managing marine invasive species through public participation: Lionfish derbies as a case study. Marine Policy, 74: 158-164. DOI: https://doi.org/10.1016/j.marpol.2016.09.027

Martin, V, Christidis, L, Lloyd, D and Pecl, G. 2016a. Understanding drivers, barriers and information sources for public participation in marine citizen science. Journal of Science Communication, 15(2): A02. DOI: https://doi.org/10.22323/2.15020202

Martin, V, Lloyd, D, Pecl, GT and Christidis, L. 2015. Deliberate design must include audience research: key considerations for marine citizen science projects in Australia. 2015 Australian Citizen Science Conference (p. 6).

Martin, V, Smith, L, Bowling, A, Christidis, L, Lloyd, D and Pecl, G. 2016b. Citizens as scientists: what influ- ences public contributions to marine research? Science Communication, 38(4): 495-522. DOI: https://doi. org/10.1177/1075547016656191

Martin, VY, Christidis, L and Pecl, GT. 2016c. Public interest in marine citizen science: is there potential for growth? BioScience, 66(8): 683-692. DOI: https://doi. org/10.1093/biosci/biw070

NOAA. 2018. Available at https://oceanservice.noaa. gov/facts/exploration.html. [Last Accessed 1 March, 2019]

Nursey-Bray, M, Palmer, R and Pecl, G. 2018. Spot, log, map: Assessing a marine virtual citizen science program against Reed's best practice for stakeholder participation in environmental management. Ocean and Coastal Management, 151(1-9). DOI: https://doi. org/10.1016/j.ocecoaman.2017.10.031

Pocock, MJ, Chandler, M, Bonney, R, Thornhill, I, Albin, A, August, T, Bachman, S, Brown, PM, Cunha, DGF, Grez, A and Jackson, C. 2018. A vision for global biodiversity monitoring with citizen science. Advances in Ecological Research, 59: 169-223. DOI: https://doi. org/10.1016/bs.aecr.2018.06.003

R Core Team. 2017. R: A language and environment for statistical computing. Vienna, Austria: R Foundation for Statistical Computing.

Roy, HE, Pocock, MJ, Preston, CD, Roy, DB, Savage, J, Tweddle, JC and Robinson, LD. 2012. Understanding citizen science and environmental monitoring. In Final report on behalf of UK Environmental Observation Framework, NERC Centre for Ecology \& Hydrology and Natural History Museum.

Schläppy, ML, Loder, J, Salmond, J, Lea, A, Dean, AJ and Roelfsema, CM. 2017. Making waves: marine citizen science for impact. Frontiers in Marine Science, 4(146). DOI: https://doi.org/10.3389/fmars.2017.00146

Shamir, L, Yerby, C, Simpson, R, von Benda-Beckmann, AM, Tyack, P, Samarra, F, Miller, $\mathbf{P}$ and Wallin, J. 2014. Classification of large acoustic datasets using machine learning and crowdsourcing: Application to whale calls. The Journal of the Acoustical Society of America, 135(2): 953-962. DOI: https://doi. org/10.1121/1.4861348

Shirk, JL, Ballard, HL, Wilderman, CC, Phillips, T, Wiggins, A, Jordan, R, McCallie, E, Minarchek, M, Lewenstein, BV, Krasny, ME and Bonney, R. 2012. Public participation in scientific research: a framework for deliberate design. Ecology and Society, 17(2): 29. DOI: https://doi.org/10.5751/ES-04705170229

Silvertown, J. 2009. A new dawn for citizen science. Trends in ecology \& evolution, 24(9): 467-471. DOI: https:// doi.org/10.1016/j.tree.2009.03.017

Thiel, M, Penna-Díaz, MA, Luna-Jorquera, G, Salas, S, Sellanes, J and Stotz, W. 2014. Citizen scientists and marine research: volunteer participants, their contributions, and projection for the future. In Hughes, RN, Hughes, DJ and Smith, IP (eds.), Oceanography and Marine Biology: An Annual Review, 52: 257-314. DOI: https://doi.org/10.1201/b17143 
Toh, TC, Ng, CSL, Loke, HX, Taira, D, Toh, KB, Afiq-Rosli, L, Du, RCP, Cabaitan, P, Sam, SQ, Kikuzawa, YP and Chou, LM. 2017. A cost-effective approach to enhance scleractinian diversity on artificial shorelines. Ecological engineering, 99: 349-357. DOI: https://doi. org/10.1016/j.ecoleng.2016.11.066

United Nations. 2017. Factsheet: People and Oceans. In The Ocean Conference, New York, June 5-9, 2017.
West, SE and Pateman, RM. 2016. Recruiting and retaining participants in citizen science: What can be learned from the volunteering literature? Citizen Science: Theory and Practice, 1(2), 15: 1-10. DOI: https://doi. org/10.5334/cstp.8

Wickham, H. 2016. ggplot2: Elegant Graphics for Data Analysis. Springer-Verlag, New York. DOI: https://doi. org/10.1007/978-3-319-24277-4_9

\footnotetext{
How to cite this article: Sandahl, A and Tøttrup, AP. 2020. Marine Citizen Science: Recent Developments and Future Recommendations. Citizen Science: Theory and Practice, 5(1): 24, pp. 1-11. DOI: https://doi.org/10.5334/cstp.270

Copyright: () 2020 The Author(s). This is an open-access article distributed under the terms of the Creative Commons Attribution 4.0 International License (CC-BY 4.0), which permits unrestricted use, distribution, and reproduction in any medium, provided the original author and source are credited. See https://creativecommons.org/licenses/by/4.0/.
} 